CLINICAL STUDY

\title{
Age-associated changes in hypothalamic-pituitary-testicular function in middle-aged and older men are modified by weight change and lifestyle factors: longitudinal results from the European Male Ageing Study
}

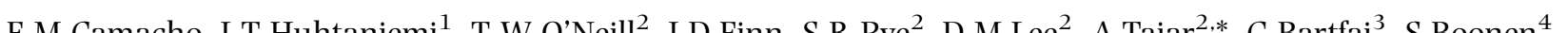

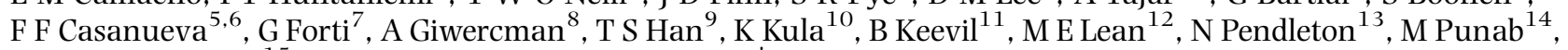
D Vanderschueren $^{15}$, F C W Wu and the EMAS Group ${ }^{\dagger}$

Andrology Research Unit, Institute of Human Development, Centre for Endocrinology and Diabetes, University of Manchester, Old St Mary's Building, Hathersage Road, Manchester M13 9WL, UK, ${ }^{1}$ Department of Surgery and Cancer, Imperial College London, Hammersmith Campus, London, UK, ${ }^{2}$ ARUK Epidemiology Unit, University of Manchester, Manchester, UK, ${ }^{3}$ Department of Obstetrics, Gynaecology and Andrology, Albert Szent-Györgyi Medical University, Szeged, Hungary, ${ }^{4}$ Department of Geriatric Medicine, Catholic University of Leuven, Leuven, Belgium, ${ }^{5}$ Department of Medicine, University of Santiago de Compostela, Santiago de Compostela, Spain, ${ }^{6}$ CIBER de Fisiopatologia Obesidad y Nutricion (CB06/03), Instituto Salud Carlos III, Santiago de Compostela, Spain, ${ }^{7}$ Endocrinology Unit, Department of Clinical Physiopathology, University of Florence, Florence, Italy, ${ }^{8}$ Reproductive Medicine Centre, Skåne University Hospital, University of Lund, Lund, Sweden, ${ }^{9}$ Department of Endocrinology, University College London, London, UK, ${ }^{10}$ Department of Andrology and Reproductive Endocrinology, Medical University of Lodz, Lodz, Poland, ${ }^{11}$ Department of Biochemistry, University Hospital of South Manchester, Manchester, UK, ${ }^{12}$ Department of Human Nutrition, University of Glasgow, Glasgow, UK, ${ }^{13}$ School of Community Based Medicine, University of Manchester, Salford Royal NHS Trust, Salford, UK, ${ }^{14}$ Andrology Unit, United Laboratories of Tartu University Clinics, Tartu, Estonia and ${ }^{15}$ Department of Andrology and Endocrinology, Catholic University of Leuven, Leuven, Belgium

(Correspondence should be addressed to F C W Wu; Email: frederick.wu@manchester.ac.uk)

*(A Tajar is now at Centre for Statistics in Medicine, University of Oxford, Oxford, UK)

${ }^{\dagger}$ (The contributors to the EMAS Group are given in the Acknowledgements section)

\begin{abstract}
Objective: Health and lifestyle factors are associated with variations in serum testosterone levels in ageing men. However, it remains unclear how age-related changes in testosterone may be attenuated by lifestyle modifications. The objective was to investigate the longitudinal relationships between changes in health and lifestyle factors with changes in hormones of the reproductive endocrine axis in ageing men.

Design: A longitudinal survey of 2736 community-dwelling men aged 40-79 years at baseline recruited from eight centres across Europe. Follow-up assessment occurred mean ( \pm s.D. $) 4.4 \pm 0.3$ years later.

Results: Paired testosterone results were available for 2395 men. Mean ( \pm s.D.) annualised hormone changes were as follows: testosterone $-0.1 \pm 0.95 \mathrm{nmol} / \mathrm{l}$; free testosterone (FT) -3.83 $\pm 16.8 \mathrm{pmol} / \mathrm{l}$; sex hormone-binding globulin (SHBG) $0.56 \pm 2.5 \mathrm{nmol} / \mathrm{l}$ and LH $0.08 \pm 0.57 \mathrm{U} / \mathrm{l}$. Weight loss was associated with a proportional increase, and weight gain a proportional decrease, in testosterone and SHBG. FT showed a curvilinear relationship to weight change; only those who gained or lost $\geq 15 \%$ of weight showed a significant change (in the same direction as testosterone). Smoking cessation was associated with a greater decline in testosterone than being a non-smoker, which was unrelated to weight change. Changes in number of comorbid conditions or physical activity were not associated with significant alterations in hypothalamic-pituitary-testicular (HPT) axis function.

Conclusions: Body weight and lifestyle factors influence HPT axis function in ageing. Weight loss was associated with a rise, and weight gain a fall, in testosterone, FT and SHBG. Weight management appears to be important in maintaining circulating testosterone in ageing men, and obesity-associated changes in HPT axis hormones are reversible following weight reduction.
\end{abstract}

European Journal of Endocrinology 168 445-455

\section{Introduction}

The age-related decline in testosterone in men has been well documented in cross-sectional studies $(1,2)$. More recently, longitudinal studies have also confirmed that testosterone declines as individuals age $(3,4,5,6,7,8)$. Despite the ill-defined aetiological mechanism(s) and clinical significance associated with this phenomenon, or the continuing uncertainties surrounding the risks vs benefits of testosterone treatment in older men (9), 
these findings have fuelled a substantial worldwide increase in testosterone prescription $(10,11,12,13)$. Testosterone decline may not be an inevitable part of ageing, being related to adverse health and lifestyle factors, such as obesity; it may, therefore, be potentially preventable and reversible $(5,6,7,14)$.

Few studies have investigated the relationships between age-related transitions in testosterone and health or lifestyle changes, which could provide a greater understanding of the directionality of these associations and elucidate potential underlying mechanisms. The Massachusetts Male Aging Study (MMAS) reported that a $4-5 \mathrm{~kg} / \mathrm{m}^{2}$ increase in BMI had a comparable negative impact on testosterone as 10 years of ageing (7). MMAS also reported that weight gain was associated with subsequently lower levels of testosterone than remaining non-obese $(5,6)$. In obese diabetic patients, interventional weight loss regimes resulted in increased testosterone (15). However, it is not known whether 'unsupervised' weight loss in the general population would have a similar impact on testosterone. If so, there may be potentially important clinical and public health implications.

While the concentration of testosterone is often the sole focus of clinical decisions, it is important to consider a broader ensemble of changes in the endocrine reproductive axis. Individual hormones of the hypothalamic-pituitary-testicular (HPT) axis are tightly regulated by feedback / feedforward relationships (16). Different components of HPT function may 'age' differently and/or respond differentially to health and lifestyle modifications. The age-related increase in sex hormone-binding globulin (SHBG) (17), and its fluctuation in response to changes in metabolic status, can influence bioavailability of testosterone and contribute to alterations in HPT axis function $(18,19,20,21,22)$.

We have previously investigated the cross-sectional relationships of HPT axis hormones with age, and health and lifestyle factors, in a sample of community-dwelling middle-aged and elderly men (1). Obesity and comorbidity were found to be linked to multiple alterations in HPT axis function. To extend these findings, we now report the longitudinal relationships between hormone changes with alterations in health status and lifestyle factors. The aim was to elucidate the aetiological mechanism(s) of the age-related decline in testosterone by determining whether and to what extent lifestyle factors could impact on HPT axis function. In addition, we aimed to investigate whether the directionality of these relationships could be established.

\section{Materials and methods}

The methodology of phase 1 and 2 of the European Male Ageing Study (EMAS) has been described in detail elsewhere $(23,24)$.

\section{Study design and population sampling}

Briefly, 3369 men aged 40-79 years were recruited using stratified random sampling from eight European centres: Manchester (UK), Leuven (Belgium), Malmö (Sweden), Tartu (Estonia), Lodz (Poland), Szeged (Hungary), Florence (Italy) and Santiago de Compostela (Spain). Of the men recruited, 193 died and the remaining 3176 men were invited to attend for follow-up $4.4 \pm 0.3$ years (range 3.0-5.7 years) later (24). A total of $2736(86.1 \%)$ men participated in the follow-up study, with 334 having been lost to follow-up (unrecorded reasons) and 106 having been institutionalised/too frail. Ethical approval for the study was obtained for each centre, as per the regulations of the local institutions.

\section{Hormone measurements}

A single fasting morning (before $1000 \mathrm{~h}$ ) venous blood sample was obtained at baseline and follow-up. Testosterone was measured by liquid chromatographytandem mass spectrometry (LC-MS/MS) (25), with paired baseline and follow-up samples analysed simultaneously. LH and SHBG were measured by the E170 platform electrochemiluminescence immunoassay (Roche Diagnostics). Free testosterone (FT) was calculated from testosterone, SHBG and albumin, using the Vermeulen formula (26). Intra- and inter-assay coefficients of variation were as follows: testosterone 4.0 and 5.6\%; SHBG 1.7 and 3.2\% and LH 1.9 and $3.0 \%$ respectively $(1,25)$. Stability of samples during long-term storage was established with no evidence of any systematic drift with time.

\section{Other measurements and data collection}

Data on medical conditions, medications, smoking, alcohol consumption and physical activity (Physical Activity Scale for the Elderly (PASE) (27)) were collected by self-completed and interviewer-assisted questionnaires (23). Standing height, weight and waist circumference (WC) were measured as described before (23). Briefly, body weight was measured to the nearest $0.1 \mathrm{~kg}$ using an electronic scale (SECA, model no. 8801321009, SECA UK Ltd, Birmingham, UK) and height to the nearest $1 \mathrm{~mm}$ using a stadiometer (Leicester Height Measure, SECA UK Ltd). BMI was calculated as body weight $(\mathrm{kg})$ divided by the square of height $(\mathrm{m})$. Each centre's electronic scales and stadiometers were calibrated on a monthly basis. WC was recorded with an anthropometric tape measure - the median of three measurements was used. The impact of $10 \%$ change in weight or WC was initially explored, as this was regarded as 'moderate' weight loss in previous studies $(28,29)$. Participants were classified as having either none or $\geq 1$ comorbidity at each visit (1). Change in physical activity was investigated as tertiles of change 


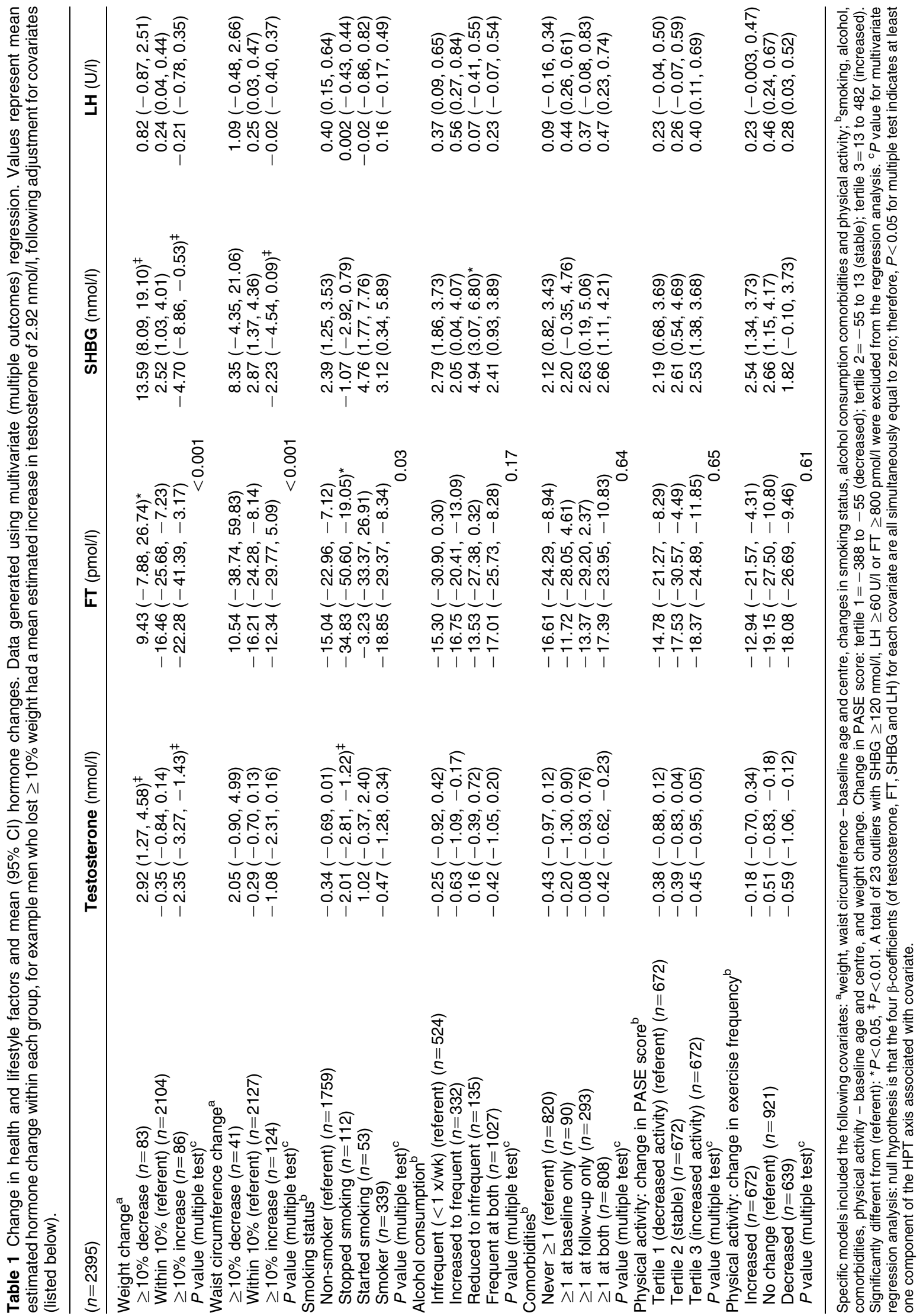


in PASE score and participants assigned to one of three groups accordingly (increased, decreased or no change).

\section{Statistical analysis}

Differences in cohort characteristics between baseline and follow-up were determined using the paired $t$-test or $\chi^{2}$ test - as appropriate to the data. Hormone changes were treated as continuous variables and calculated as follow-up measurement - baseline measurement. Linear (age as a continuous variable) and non-linear (age (2)) trends between hormone changes and baseline age were investigated using linear regression. Unadjusted relationships between hormone changes and each of the health/lifestyle changes across the four baseline age bands (40-49, 50-59, 60-69 and 70-79 years) were initially evaluated graphically. To reflect the functional links between the components of the HPT axis under investigation, multivariate (multiple outcomes) linear regression was used to jointly regress the four outcome variables (changes in testosterone, FT, SHBG and LH) simultaneously, as described previously (1). This extension to simple linear regression generates a 'multiple test statistic' denoting whether the four coefficients (one for each hormone) obtained are simultaneously equal to zero. A $P$ value of $<0.05$ for the multiple test statistic suggests that at least one of the four hormones is significantly associated with the independent variable. Separate multivariate regression models were then carried out to investigate the relationships between changes in each of the health/ lifestyle factors (as categorical variables) and changes in the four hormones. Referent categories in each model are denoted in Table 1. Results were expressed as mean hormone changes and 95\% CIs and considered statistically significant if the null hypothesis could be rejected at the 0.05 (two-tailed) level. Each regression model was adjusted for potential confounders: baseline age, centre and BMI, where relevant. Additional adjustments for confounders included changes in weight, smoking status, alcohol consumption, comorbidities and physical activity (see Tables 1 and 2 footnotes for further details). To obtain a broader overview of the relationship between weight change and HPT axis function, a multivariate regression model (as described earlier) was used to investigate changes in hormones at seven mutually exclusive levels of weight change $( \pm>15 \%, \pm 10-15 \%, \pm 5-10 \%$ and 'no change' (within 5\% of baseline)). The independent variable denoting levels of weight change was a single categorical variable; men in the 'no change' group were the referent category. These relationships were also evaluated graphically. Sub-analyses, using multivariate regression models as described earlier, were also carried out after stratifying by baseline obesity. Multinomial logistic regression was used to investigate the relationships between (continuous) baseline hormone levels and the likelihood of a subsequent change in weight compared with the likelihood of having 'stable' weight; this was then repeated for WC change. Statistical analyses were conducted using STATA SE version 10 (StataCorp, College Station, TX, USA).

\section{Results}

\section{Cohort characteristics}

Men who had diagnosed medical conditions or were on medications known to affect pituitary-testicular function or hormone clearance at baseline $(n=106)$ or during follow-up $(n=155)$ were excluded from this analysis, using the same criteria as our previous crosssectional analysis (1). Men who did not have testosterone results at both time points were also excluded $(n=80)$. Characteristics of the analysis sample are summarised in Table 3. Mean (S.D.) age of the analysis sample at study recruitment was 58.4 (10.5) years. Twenty-four per cent of men were obese (BMI $\geq 30 \mathrm{~kg} / \mathrm{m}^{2}$ ) at baseline and $27 \%$ at follow-up. There were fewer smokers (17 vs $20 \%$ ) but a greater percentage of frequent drinkers (67 vs $59 \%$ ) at followup. The proportion of men reporting $\geq 1$ comorbidity increased from 45 to $55 \%$.

\section{Hormone levels}

Mean (s.D.) testosterone was 16.9 (6.0) $\mathrm{nmol} / \mathrm{l}$ at baseline, and decreased to $16.5(6.1) \mathrm{nmol} / \mathrm{l}$ at follow-up

Table 2 Mean $(95 \% \mathrm{Cl})$ hormone changes by \% weight change.

\begin{tabular}{lcccc}
\hline & $\begin{array}{c}\text { Mean testosterone } \\
\text { change }(\mathrm{nmol} / \mathrm{l})\end{array}$ & $\begin{array}{c}\text { Mean FT } \\
\text { change }(\mathrm{pmol} / \mathrm{l})\end{array}$ & $\begin{array}{c}\text { Mean SHBG } \\
\text { change }(\mathrm{nmol} / \mathrm{l})\end{array}$ & $\begin{array}{c}\text { Mean LH } \\
\text { change }(\mathrm{U} / \mathrm{l})\end{array}$ \\
\hline Lost $\geq 15 \%(n=22)$ & $5.75(1.32,10.18)^{\star}$ & $51.78(1.71,101.85)^{\star}$ & $14.77(2.39,27.15)^{\star}$ & $2.21(-0.58,5.01)$ \\
Lost $\geq 10$ to $<15 \%(n=61)$ & $1.96(-0.47,4.39)$ & $-5.06(-39.17,29.06)$ & $13.19(7.06,19.32)^{\ddagger}$ & $0.34(-1.51,2.20)$ \\
Lost $\geq 5$ to $<10 \%(n=288)$ & $0.28(-0.22,0.77)^{\ddagger}$ & $-13.94(-21.40,-6.48)$ & $5.32(3.40,7.24)^{\ddagger}$ & $0.87(0.17,1.60)$ \\
Within $5 \%($ referent $)(n=1554)$ & $-0.33(-0.79,0.13)$ & $-16.85(-27.02,-6.68)$ & $2.61(1.06,4.15)$ & $0.16(-0.05,0.37)$ \\
Gained $\geq 5$ to $<10 \%(n=262)$ & $-1.20(-2.07,-0.33)^{\star}$ & $-16.92(-29.66,-4.18)$ & $-1.26(-2.90,0.58)^{\ddagger}$ & $-0.005(-0.27,0.26)$ \\
Gained $\geq 10$ to $<15 \%(n=69)$ & $-1.89(-3.14,-0.63)^{\star}$ & $-16.55(-46.45,13.35)$ & $-3.84(-8.63,0.95)^{\ddagger}$ & $-0.26(-1.10,0.57)$ \\
Gained $\geq 15 \%(n=17)$ & $-4.35(-6.97,-1.73)^{\star}$ & $-47.10(-136.91,42.72)$ & $-8.41(-18.73,1.90)^{\star}-0.004(-1.00,0.99)$ \\
\hline
\end{tabular}

Significantly different from (referent): ${ }^{\star} P<0.05,{ }^{\ddagger} P<0.01$. Models included the following covariates: baseline age and centre, changes in smoking status, alcohol consumption, comorbidities and physical activity. A total of 23 outliers with SHBG $\geq 120 \mathrm{nmol} / \mathrm{l}, \mathrm{LH} \geq 60 \mathrm{U} / \mathrm{l}$ or FT $\geq 800 \mathrm{pmol} / \mathrm{l}$ were excluded from the regression analysis. 
Table 3 Cohort characteristics at baseline and follow-up.

\begin{tabular}{|c|c|c|}
\hline$(n=2395)$ & $\begin{array}{l}\text { Baseline } \\
n / N(\%)\end{array}$ & $\begin{array}{l}\text { Follow-up } \\
n / N(\%)\end{array}$ \\
\hline Age (years) ${ }^{a}$ & $58.4(10.5)$ & $62.8(10.5)$ \\
\hline \multicolumn{3}{|l|}{ Age band (years): } \\
\hline $40-49$ & $641 / 2395(26.8)$ & $314 / 2395(13.1)$ \\
\hline $50-59$ & 706/2395 (29.5) & $752 / 2395(31.4)$ \\
\hline $60-69$ & 607/2395 (25.3) & 649/2395 (27.1) \\
\hline $70+$ & 441/2395 (18.4) & 680/2395 (28.4) \\
\hline Weight $(\mathrm{kg})^{\mathrm{a}}$ & $84.0(13.7)$ & $83.9(14.4)$ \\
\hline BMI $\left(\mathrm{kg} / \mathrm{m}^{2}\right)^{\mathrm{a}}$ & $27.6(4.0)$ & $27.8(4.2)^{\star}$ \\
\hline Obese $\left(\mathrm{BMI} \geq 30 \mathrm{~kg} / \mathrm{m}^{2}\right)$ & $568 / 2374(23.9)$ & $615 / 2305(26.7)^{\star}$ \\
\hline Waist circumference $(\mathrm{cm})^{\mathrm{a}}$ & $98.2(10.8)$ & $99.6(11.6)^{*}$ \\
\hline Obese $(\mathrm{WC} \geq 102 \mathrm{~cm})$ & $815 / 2375$ (34.3) & $926(39.8)^{\star}$ \\
\hline Current smoker & 476/2373 (20.1) & $402 / 2310(17.4)^{\star}$ \\
\hline$\geq 1$ Comorbidity & 1069/2362 (45.3) & $1116 / 2047(54.5)^{\star}$ \\
\hline Frequent alcohol drinker & $1407 / 2384(59.0)$ & $1375 / 2049(67.1)^{\star}$ \\
\hline $\begin{array}{l}\text { Physical activity } \\
\text { (PASE score) }^{\mathrm{a}}\end{array}$ & $204(89)$ & $181(96)^{\star}$ \\
\hline Testosterone $(\mathrm{nmol} / /)^{\mathrm{a}}$ & $16.9(6.0)$ & $16.5(6.1)^{\star}$ \\
\hline Free testosterone $(\mathrm{pmol} / /)^{\mathrm{a}}$ & $303.4(87.1)$ & $286.3(88.8)^{\star}$ \\
\hline $\begin{array}{l}\text { Sex hormone-binding globulin } \\
(\mathrm{nmol} / /)^{\mathrm{a}}\end{array}$ & $41.6(18.8)$ & $44.2(20.2)^{\star}$ \\
\hline $\mathrm{LH}\left(\mathrm{U} / \mathrm{I}^{\mathrm{a}}\right.$ & $5.8(3.8)$ & $6.2(4.5)^{\star}$ \\
\hline
\end{tabular}

${ }^{\star} P<0.001$. $P$ value for difference calculated using $t$-test (continuous) or $\chi^{2}$ test (categorical); BMI $\left(\mathrm{kg} / \mathrm{m}^{2}\right)$; WC, waist circumference $(\mathrm{cm})$. Smoking status: current smoker (cigarettes), otherwise 'non-smoker' (ex-smoker or never smoked). Alcohol intake: frequent ( $\geq 5$ drinks/week), otherwise 'infrequent' ( $<1$ drink/week or one to four drinks/week).

aMean (S.D.).

$(P<0.001)$ (Table 3$)$; the mean change was -0.44 (4.1) nmol/l. Mean calculated FT also declined from $303.4(87.1)$ to $286.3(88.8) \mathrm{pmol} / \mathrm{l}$; the mean change was $-16.85(72.7) \mathrm{pmol} / \mathrm{l}(P<0.001)$. SHBG increased during follow-up from 41.6 (18.8) nmol/l to 44.2 $(20.2) \mathrm{nmol} / \mathrm{l}$; the mean change was 2.47 (10.9) nmol/l $(P<0.001)$. LH increased from 5.8 (3.8) to $6.2(4.5)$ $\mathrm{U} / \mathrm{l}$; the mean change was $0.33(2.5) \mathrm{U} / \mathrm{l}(P<0.001)$. The mean annualised change for each hormone was testosterone -0.1 (0.95) nmol/l; FT - 3.83 (16.8) $\mathrm{pmol} / \mathrm{l}$; SHBG 0.56 (2.5) nmol/l and LH 0.08 (0.57) U/l. The mean percentage change per year for each hormone was testosterone $-0.04 \%$, FT $-0.77 \%$, SHBG $1.92 \%$ and LH $2.3 \%$.

\section{Age}

The age-stratified hormonal changes are shown in Fig. 1. Beyond 50 years of age, there was a greater decrease in testosterone and FT. SHBG increase was stable across the age bands. $\mathrm{LH}$ showed a progressive increase after 50 years, with a more substantial elevation in the oldest group. The decline in testosterone and increase in LH showed a significant non-linear trend with age (testosterone $P=0.03$; LH $P<0.001$ ). Change in FT and SHBG did not show a significant age trend (linear: FT $P=0.22$; SHBG $P=0.23$; non-linear: FT $P=0.17$; SHBG $P=0.25)$. Adjustment for confounders did not alter these relationships.

\section{Weight}

The relationships between change in weight and hormonal changes are shown in Fig. 2. Following adjustment for potential confounders, men whose weight decreased by $\geq 10 \%$ (mean decrease of $13.7 \mathrm{~kg}$ ) showed an increase in testosterone $(2.9 \mathrm{nmol} / \mathrm{l})$ and SHBG $(13.6 \mathrm{nmol} / \mathrm{l})$, which were significantly different from the respective changes among men whose weight remained within $10 \%$ of baseline: testosterone $-0.4 \mathrm{nmol} / \mathrm{l}$ and SHBG $2.5 \mathrm{nmol} / \mathrm{l}(P<0.01$ for both) (Table 1). An increase of $\geq 10 \%$ in weight (mean increase of $12.3 \mathrm{~kg}$ ) was associated with a decrease in testosterone $(-2.4 \mathrm{nmol} / \mathrm{l})$ and SHBG $(-4.7 \mathrm{nmol} / \mathrm{l})$, which were significantly different from the respective changes in men with 'stable' weight $(P<0.01$ for both).

\section{Waist circumference}

Multiple testing showed a strong association between change in WC and changes in HPT axis function $(P<0.001)$ (Table 1). The relationships between a decrease in WC and hormone changes were similar to those for weight loss in direction and magnitude. The hormone changes associated with WC increase were more modest, although in the same direction, than those associated with weight gain.

\section{Smoking}

Men who stopped smoking showed a greater decrease than non-smokers in testosterone $(-2.0 \mathrm{vs}-0.3 \mathrm{nmol} / \mathrm{l}$; $P<0.01)$ and FT $(-34.8$ vs $-15.0 \mathrm{pmol} / \mathrm{l} ; \quad P<0.05)$ (Table 1). Starting smoking was not significantly associated with hormone changes.

\section{Alcohol}

Multiple testing indicated that there was no significant relationship between change in alcohol consumption and change in HPT axis function $(P=0.17)$. However, frequent drinkers who decreased their frequency of alcohol consumption during follow-up showed a significantly greater increase in SHGB than men who remained infrequent drinkers at both time points (4.9 vs $2.8 \mathrm{nmol} / \mathrm{l} ; \mathrm{P}<0.05$ ) (Table 1).

\section{Other health and lifestyle factors}

There was no association between changes in number of comorbidities, physical activity or exercise frequency (Table 1) with hormone changes.

\section{Levels of weight change}

The weight/hormone relationship was further investigated at seven different incremental levels of weight 

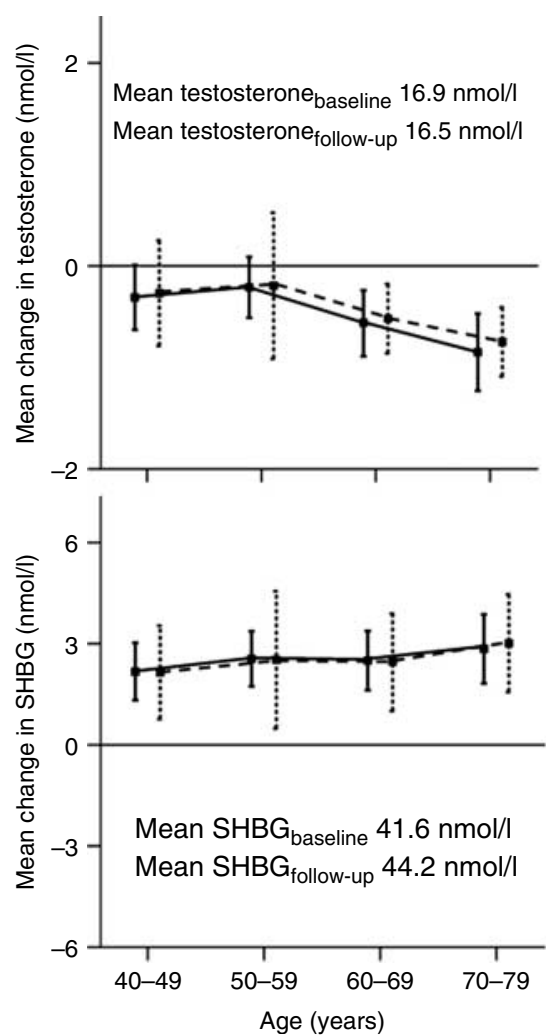

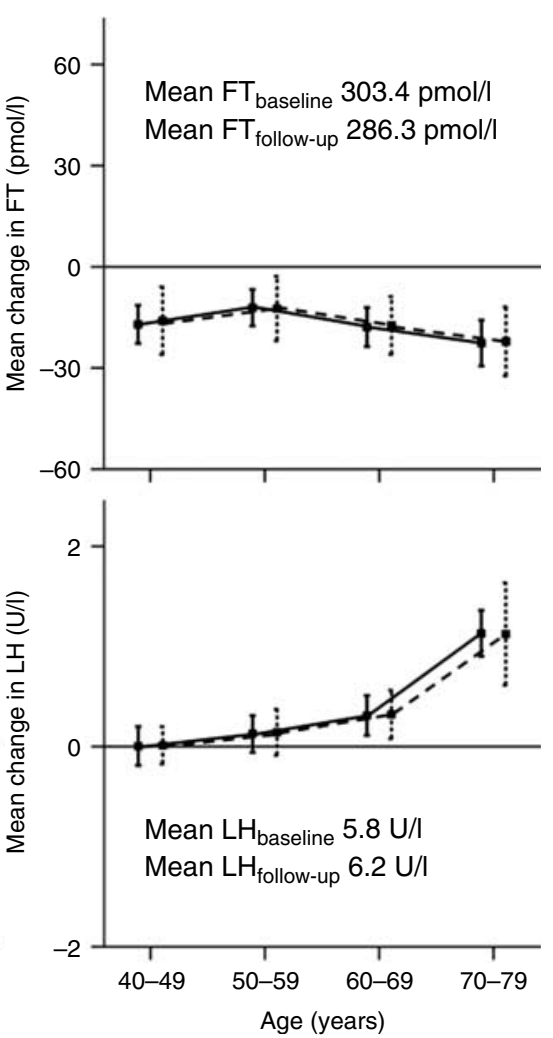

Figure 1 Unadjusted and adjusted relationships between hormone changes and age. This shows the mean hormone changes at 10 -year age bands with $95 \% \mathrm{Cl}$ (vertical bars) in 2395 men. Testosterone and FT appeared to show a greater decrease beyond 50 years, SHBG showed an increase that was relatively stable across the age bands and $\mathrm{LH}$ showed a progressive increase after 50 years, with an apparent inflection point around 70 years. Testosterone $(P=0.03)$ and $\mathrm{LH}(P<0.001)$ showed a significant non-linear trend with age. Adjustment for potential confounders (BMI, smoking status and centre) did not alter these relationships. Dashed lines represent adjusted values. change $(>15 \%$ loss, $10-15 \%$ loss, $5-10 \%$ loss, within $5 \%, 5-10 \%$ gain, $10-15 \%$ gain, $>15 \%$ gain). Figure 3 summarises the overall dose-response relationships between weight and hormone changes. Both testosterone and FT showed a curvilinear (cubic) relationship. However, there were differences between testosterone and FT. Losing 5\% of weight was associated with a significant increase in testosterone, which increased further with additional weight loss. Weight gain mirrored this pattern with progressive decline in testosterone. By contrast, there appeared to be a threshold relationship with FT whereby only a weight
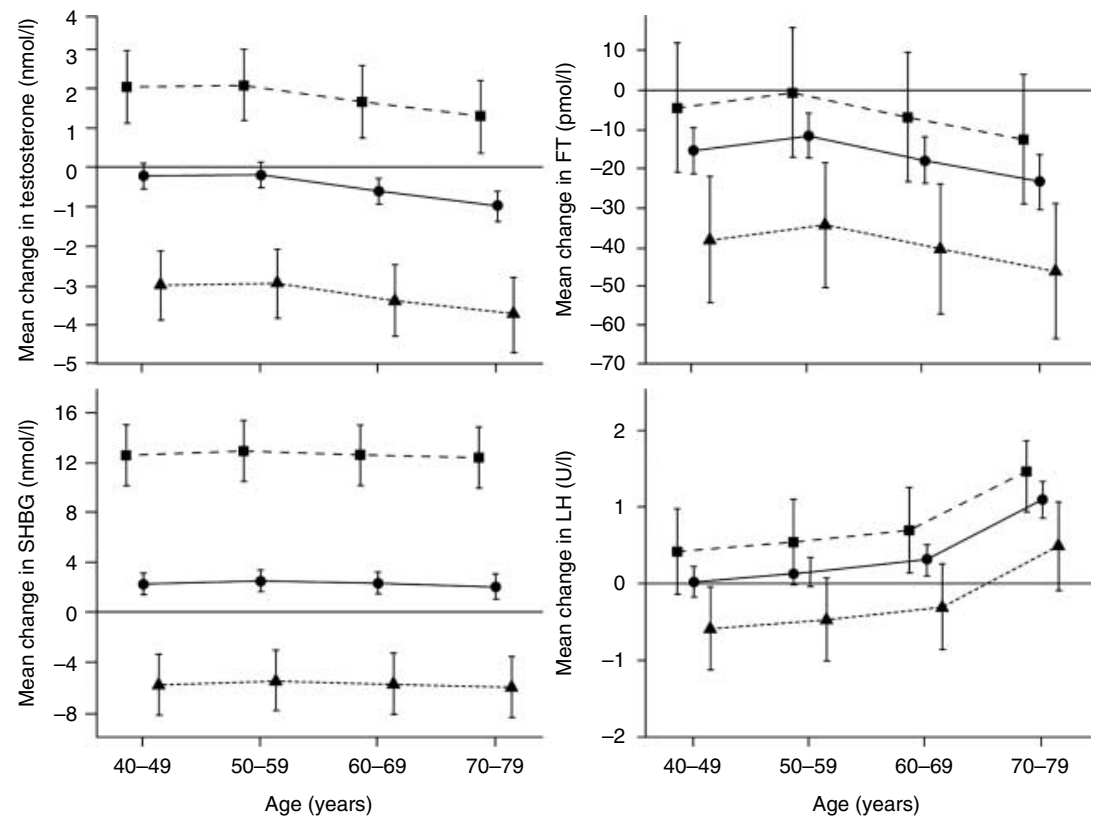

Figure 2 Relationships between age, weight changes and hormone changes. Values represent the unadjusted mean hormone change at 10 -year age bands with $95 \% \mathrm{Cl}$ (vertical bars). A total of 23 outliers with $\mathrm{SHBG} \geq 120 \mathrm{nmol} / \mathrm{l}, \mathrm{LH} \geq 60 \mathrm{U} / \mathrm{l}$ or $\mathrm{FT}$ $\geq 800 \mathrm{pmol} / \mathrm{l}$ were excluded from these graphs. The cohort was stratified according to weight change into three groups: lost $\geq 10 \%$ weight (closed square), stable weight (within $10 \%$ of baseline, closed circle) and gained $\geq 10 \%$ weight (closed triangle). Testosterone and SHBG increased by significantly more among men whose weight decreased than men whose weight did not change by $\geq 10 \%$. Men whose weight increased showed a greater decline in testosterone, FT and SHBG than men with stable weight. 

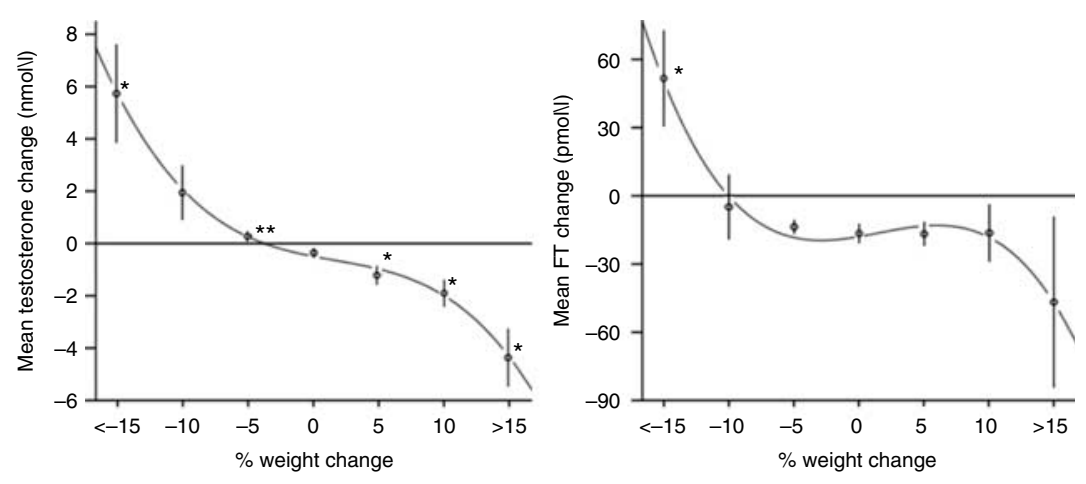

Figure 3 Mean hormone changes by \% weight change. The cohort was stratified, according to increasing levels of weight gain or loss, into seven separate groups: loss of $>15 \%$, loss of $10-15 \%$, loss of $5-10 \%$, within $5 \%$, gain of $5-10 \%$, gain of $10-15 \%$ and gain of $>15 \%$. The number ' 0 ' on the $x$-axis represents the 'within 5\%' group. Error bars represent \pm 1 S.E.M. A total of 23 outliers with $\mathrm{SHBG} \geq 120 \mathrm{nmol} / \mathrm{l}, \mathrm{LH} \geq 60 \mathrm{U} / \mathrm{l}$ or FT $\geq 800 \mathrm{pmol} / \mathrm{l}$ were excluded from the
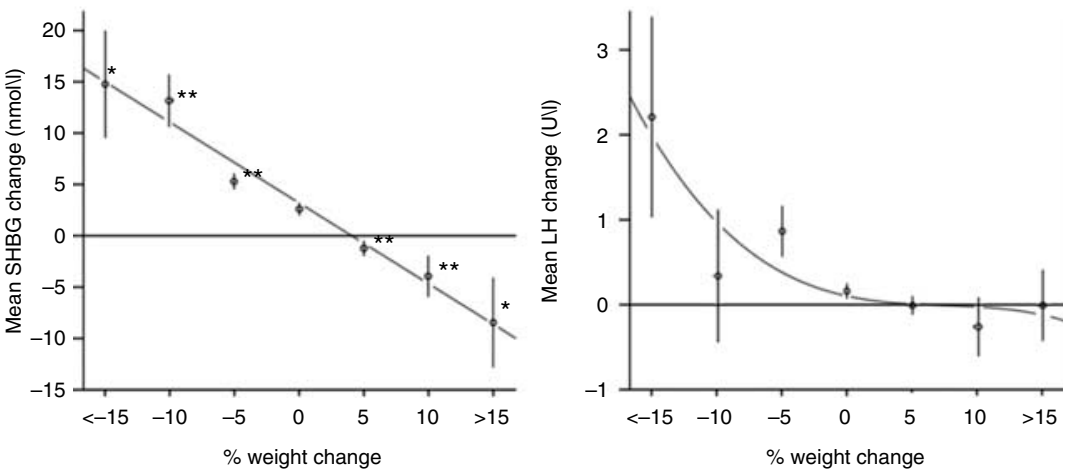
regression analysis. Data are adjusted for baseline age and centre, changes in smoking status, alcohol consumption comorbidities and physical activity. Weight loss was associated with hormone rise and weight gain with hormone fall, the extent of which increased with the level of weight change. Testosterone and FT showed cubic, SHBG a linear and $\mathrm{LH}$ a cubic relationship with weight change. FT changed only with the highest level of weight change $(15 \%)$, which is a reflection of its derivation from testosterone and SHBG. Lines fitted using SPSS v.16.0. Significantly different from (referent): ${ }^{\star} P<0.05,{ }^{\star \star} P<0.01$

loss or gain of $\geq 15 \%$ was associated with a notable change in FT. Men who lost $\geq 15 \%$ weight showed a significant increase in FT $(51.8 ; 95 \%$ CI 1.7 , $101.9 \mathrm{pmol} / \mathrm{l})$, in contrast to the decrease among men with stable weight $(-16.9 ; 95 \%$ CI -27.0 , $-6.7 \mathrm{pmol} / \mathrm{l})$, and those whose weight increased by $\geq 15 \%$ showed a greater decline in FT $(-47.1 ; 95 \%$ CI -136.9, 42.7 pmol) (Table 2). SHBG change showed a linear relationship with weight change (Fig. 3) - men who lost the most weight showed the greatest increase and men who gained the most weight showed the greatest decline. The relationship between weight change and LH change was curvilinear (Fig. 3) - weight loss appeared to be associated with an exponential increase in LH whereas weight gain was not associated with LH change. Men who lost $\geq 15 \%$ of weight showed a tenfold greater increase in LH $(2.2 ; 95 \%$ CI -0.6 , $5.0 \mathrm{U} / \mathrm{l})$ than men with stable weight $(0.2 ; 95 \% \mathrm{CI}$ $-0.1,0.4 \mathrm{U} / \mathrm{l})$ (Table 2).

\section{Baseline obesity and weight change}

Men who were obese at baseline showed a marginally greater increase in testosterone with $\geq 10 \%$ weight loss compared with non-obese men (3.0 vs $1.2 \mathrm{nmol} / \mathrm{l}$ ) (data not shown). Losing weight also appeared to have greater influence on FT change in obese compared with non-obese men ( 7.8 vs $-13.5 \mathrm{pmol} / \mathrm{l})$. However, these differences did not reach statistical significance (testosterone $P=0.07$; FT $P=0.17$ ). Weight gain was associated with similar changes in testosterone and FT for obese and non-obese men. However, weight gain was associated with a greater decline in SHBG in non-obese compared with obese men $(-6.3 \mathrm{vs}-3.5 \mathrm{nmol} / \mathrm{l})$, this difference also did not reach statistical significance.

\section{Baseline hormones and weight change}

None of the baseline hormone levels showed any consistent associations with subsequent weight change (data not shown). For each $10 \mathrm{pmol} / \mathrm{l}$ increase in baseline FT, there was a very small decrease in the likelihood of losing $\geq 10 \%$ weight compared with having 'stable' weight (relative risk ratio 0.96; 95\% CI 0.94, 0.99). The likelihood of an increase in body weight, or a change in WC in either direction, was not associated with baseline levels of testosterone, FT, SHBG, or LH ( $P>0.05$ for each).

\section{Discussion}

This prospective study of community-dwelling men in Europe showed that weight gain was associated with suppression of testosterone, FT and SHBG, while weight loss was associated with an increase in testosterone, FT, SHBG and LH. These reciprocal changes displayed a robust dose-response relationship between weight change and reproductive hormones, which emphasises the functional liability (and reversibility) in the HPT axis in ageing men. 
In agreement with our previous cross-sectional findings, and other longitudinal studies $(1,3,4,5,6$, $7,8,30,31,32)$, the present results confirm that testosterone and FT declined while SHBG and LH increased with age, with the mean hormone levels remaining well within the physiological range. The overall pattern of changes in the HPT axis was consistent with a progressive age-related impairment of testicular function, partially compensated for by an increase in LH. The decline in FT with age is exaggerated by the concurrent rise in SHBG. The magnitude of the observed change in testosterone $(-0.1 \mathrm{nmol} / \mathrm{l}$ per year) was modest and similar to that in previous longitudinal studies $(3,14,30,32)$.

The present longitudinal data were in agreement with other prospective studies showing that weight gain was associated with a decline in testosterone and SHBG $(5,6,7,8)$. LH was largely unchanged with weight gain, despite the significant decrease in testosterone. Weight gain (and obesity) appears to be associated with hypothalamic dysfunction, leading to blunted LH secretion and secondary or hypogonadotrophic hypogonadism (33). Reversal of this hypothalamic suppression with weight loss may thus be expected to result in a rise in testosterone through increased LH stimulation. Indeed, the most notable novel finding in this study, which had not been reported previously in the general population, is the consistent relationship between weight loss and increased testosterone, FT and LH, which was not observed in men with stable weight. This is compatible with clinical interventional studies on weight reduction strategies in obese patients (with diabetes or the metabolic syndrome) $(15,34)$.

Our results also show, for the first time in a general population cohort, that SHBG increased with weight loss as well as decreased with weight gain, modulating not only circulating levels of testosterone but also buffering FT variations associated with more modest degrees of weight changes (vide infra). It is generally accepted that obesity is associated with lower SHBG $(1,4,7)$ as a result of insulin resistance, with the high levels of circulating insulin inhibiting hepatic SHBG production (17). The present results suggest that the fluctuations in SHBG concentrations can provide robust metabolic signal-linking variations in adiposity to HPT axis function, thereby regulating androgen bioactivity through insulin signalling. This is supported by the recent finding that circulating SHBG is influenced by variations in genes involved in the regulation of lipid and carbohydrate metabolism (35). Delivery of bound hormones at target tissue sites (36) is a further possibility for an active role of SHBG in the regulation of sex steroid bioavailability.

The overall picture of HPT axis function with incremental levels of weight change (Fig. 3) shows that hormone levels varied bi-directionally in proportion to the degree of weight loss/gain. The impact of weight change (especially $>10 \%$ ) is much greater than that of ageing alone (Fig. 1). Furthermore, the apparent reversal of the age-related decline in testosterone and FT with weight loss, and its exaggeration with weight gain (Fig. 2), reaffirm our previous suggestion that decreasing testosterone with ageing is not inevitable but potentially preventable and reversible with weight management. The majority of men in this analysis showed stable weight or $<15 \%$ change, as expected in a non-interventional study. However, a significant shift in FT was only observed with more substantial $(\geq 15 \%)$ weight change. This apparent 'threshold' effect could be explained by the fact that FT is calculated from testosterone and SHBG concentrations (both of which varied independently with weight change). Thus, the significant increase in FT with $\geq 15 \%$ weight loss could reflect the steep(er) rise in testosterone, probably driven by a similar increase in LH. This LH-driven exponential increase in testosterone with more substantial weight loss exceeded the binding capacity and could therefore override the effects of a more modest linear increase in SHBG. With $\geq 15 \%$ weight gain, the greater fall in testosterone, associated with a lack of LH change (evidence for progressive hypothalamic suppression), may again explain the fall in FT despite the concurrent decrease in SHBG. In other words, any mitigating effect of SHBG changes on FT is overridden by simultaneous and greater changes in (total) testosterone. Direct measurement of FT, not currently available in this study, will be required to substantiate the current findings and allow more in-depth analyses of the contribution of changes in SHBG to changes in FT. These considerations may also account for the inconsistent relationship between FT and weight change in previous studies $(3,6,7,34,37,38)$.

Of the 568 men who were obese at baseline, only a relatively small number showed a $\geq 10 \%$ weight change during follow-up (loss: $n=30$; gain: $n=25$ ). Thus, there was insufficient analytical power to detect a statistically significant difference of the impact of weight changes between obese and non-obese men. However, our data did suggest that obese men may experience a greater increase in testosterone with weight loss compared with non-obese men (data not shown). This highlights the value of weight loss in improving HPT axis function, especially in obese men.

It is important to note that we found little association between baseline hormone levels and subsequent weight changes. This is in agreement with recent findings from the BACH survey of middle-aged men (personal communication). Findings from a recent study of menopausal women also suggested that weight gain drives hormone changes (39). Although it is not possible to prove direct causality, changes in HPT hormones appear to be driven by changes in adiposity and not vice versa.

The reason for an individual's weight change may potentially confound the relationships between weight change and hormone changes. Important reasons for 
weight changes are changes in diet and/or physical activity, smoking, alcohol consumption, general health (comorbidity), cancer cachexia and other wasting diseases and bariatric surgery. Our results show that the relationships between weight and hormone changes were not attenuated by adjustment for changes in physical activity, smoking, alcohol consumption or comorbidities. Dietary data were not available, and no subject reported undergoing bariatric surgery. Excluding men who had incident cancer or heart disease did not influence the results (data not shown). The relationships between weight and hormone changes therefore appear to be robust. Apart from body weight, other health/lifestyle factors (e.g. comorbidity and physical activity) did not show much independent influence on hormone changes. Men who stopped smoking showed a greater decline in testosterone than non-smokers. More of the men who stopped smoking gained $(\geq 10 \%)$ weight during follow-up compared with non-smokers (16 vs 3\%). However, the relationship between smoking and testosterone decline was independent of weight change.

A key strength of this study is the investigation of changes in health and lifestyle factors (as opposed to baseline predictors), with contemporaneous changes in circulating hormone levels; there are two major benefits of this approach. First, it provides a better understanding of the temporal relationship between health/ lifestyle modifications and hormone changes. Secondly, the potential impact of positive lifestyle changes (e.g. weight loss) on HPT axis function can be assessed, highlighting the public health message. A further strength is consideration of the feedback-feed-forward regulatory nature of the HPT axis by examining multiple hormones, enabling differentiation between hypothalamic and testicular malfunctions. In our previous cross-sectional study, a gas chromatographymass spectrometry method was used for measuring testosterone (1), which showed a high concordance correlation $(R=0.95, P<0.001$; data not shown) with the validated LC-MS/MS method (25) used in this analysis. In the present longitudinal study, parallel analyses of both baseline and follow-up samples, together in the same LC-MS/MS run (25), not only ensured optimal accuracy and precision (40) but also minimised inter-laboratory and methodological variations. The ability to use data from such a sizeable general population cohort in a real-world setting is another one of the study's major strengths. One limitation, however, is the relative shortage of detailed information about individuals' circumstances that could account for weight change, such as diet. It was not possible to investigate the relationship between weight and oestradiol change as mass spectrometry measurements of oestradiol were not available in the follow-up samples. Other limitations in the EMAS have been described in detail previously $(1,23)$. However, some specific issues should be highlighted when interpreting the current results. The overall retention rate of the cohort was $81.2 \%$, with a mortality-adjusted participation rate of $86.2 \%$ (31). This is comparable to other longitudinal studies of ageing (24) whose findings, like ours, are inevitably subject to some survivor bias. Exclusion of men with diagnosed medical conditions known to affect pituitary-testicular function may have resulted in overrepresentation of healthier men, which may explain why an association between number of comorbid conditions and hormone changes was not observed. The average duration of follow-up of 4.4 years in EMAS is relatively short in the context of the ageing process; longer follow-up with additional rounds of assessment is required to define the trajectory of changes of interest more accurately.

In conclusion, our results show that longitudinal changes in HPT axis function in ageing men are modified by health and lifestyle factors, which can attenuate or reverse the apparent age-related testosterone-decline. We have shown, for the first time in the general population, that moderate weight loss was associated with an increase in testosterone and more substantial $(>15 \%)$ weight loss with an increase in FT as well. This suggests that preventing obesity is important in maintaining HPT axis functioning in ageing, and furthermore, obesity-associated changes in reproductive hormones are reversible following weight reduction.

\section{Declaration of interest}

F C W Wu consulted for Bayer-Schering Healthcare, Germany; Akzo-Nobel (ORganon), The Netherlands; Pierre-Fabre Medicaments, France; Ardana Biosciences, UK; Procter and Gamble, US; and Lily-ICOS, US, and has also received research grant funding from Bayer-Schering Healthcare, Germany; Bayer-Schering; Lily-ICOS and other companies. All other authors have nothing to declare.

\section{Funding}

The European Male Aging Study is funded by the Commission of the European Communities Fifth Framework Program 'Quality of Life and Management of Living Resources' Grant QLK6-CT-2001-00258.

\section{Acknowledgements}

The authors wish to thank the men who participated in the eight countries, the research/nursing staff in the eight centres: $\mathrm{C}$ Pott (Manchester), E Wouters (Leuven), M Nilsson (Malmö), M del Mar Fernandez (Santiago de Compostela), M Jedrzejowska (Łódź), H-M Tabo (Tartu), A Heredi (Szeged) for their data collection and C Moseley (Manchester) for data entry and project co-ordination. They also thank M Lean of Glasgow for his expert advice. The EMAS Group included the following: Florence, Italy (Gianni Forti, Luisa Petrone, Giovanni Corona); Leuven, Belgium (Dirk Vanderschueren, Steven Boonen, Herman Borghs); Łódź, Poland (Krzysztof Kula, Jolanta Slowikowska-Hilczer, Renata Walczak-Jedrzejowska); London, UK (Ilpo Huhtaniemi); Malmö, Sweden (Aleksander Giwercman); Manchester, UK (Frederick Wu, Alan Silman, Neil Pendleton, Terence O'Neil, Joseph Finn, Philip Steer, Abdelouahid Tajar, David Lee, Stephen Pye, Elizabeth Camacho); Santiago de Compostela, Spain (Felipe Casanueva, Mary Lage, Ana I Castro); Szeged, Hungary (György Bartfai, Imre Földesi, Imre Fejes); Tartu, Estonia (Margus Punab, Paul Korrovitz); and Turku, Finland (Min Jang). 


\section{References}

1 Wu FCW, Tajar A, Pye SR, Silman AJ, Finn JD, O’Neill TW, Bartfai G, Casanueva F, Forti G, Giwercman A et al. Hypothalamicpituitary-testicular axis disruptions in older men are differentially linked to age and modifiable risk factors: the European Male Aging Study. Journal of Clinical Endocrinology and Metabolism 200893 2737-2745. (doi:10.1210/jc.2007-1972)

2 Kaufman JM \& Vermeulen A. The decline of androgen levels in elderly men and its clinical and therapeutic implications. Endocrine Reviews 200526 833-876. (doi:10.1210/er.2004-0013)

3 Harman SM, Metter EJ, Tobin JD, Pearson J \& Blackman MR. Longitudinal effects of aging on serum total and free testosterone levels in healthy men. Journal of Clinical Endocrinology and Metabolism 2001 86 724-731. (doi:10.1210/jc.86.2.724)

4 Feldman HA, Longcope C, Derby CA, Johannes CB, Araujo AB, Coviello AD, Bremner WJ \& McKinlay JB. Age trends in the level of serum testosterone and other hormones in middle-aged men: longitudinal results from the Massachusetts Male Aging Study. Journal of Clinical Endocrinology and Metabolism 2002 87 589-598. (doi:10.1210/jc.87.2.589)

5 Derby CA, Zilber S, Brambilla D, Morales KH \& McKinlay JB. Body mass index, waist circumference and waist to hip ratio and change in sex steroid hormones: the Massachusetts Male Ageing Study. Clinical Endocrinology 200665 125-131. (doi:10.1111/j.13652265.2006.02560.x)

6 Mohr BA, Bhasin S, Link CL, O'Donnell AB \& McKinlay JB. The effect of changes in adiposity on testosterone levels in older men: longitudinal results from the Massachusetts Male Aging Study. European Journal of Endocrinology 2006155 443-452. (doi:10.1530/eje.1.02241)

7 Travison TG, Araujo AB, Kupelian V, O’Donnell AB \& McKinlay JB. The relative contributions of aging, health, and lifestyle factors to serum testosterone decline in men. Journal of Clinical Endocrinology and Metabolism 200792 549-555. (doi:10.1210/jc.2006-1859)

8 Lapauw B, Goemaere S, Zmierczak H, Van Pottelbergh I, Mahmoud A, Taes Y, De Bacquer D, Vansteelandt S \& Kaufman JM. The decline of serum testosterone levels in community-dwelling men over 70 years of age: descriptive data and predictors of longitudinal changes. European Journal of Endocrinology 2008159 459-468. (doi:10.1530/EJE-07-0873)

9 Cunningham GR \& Toma SM. Why is androgen replacement in males controversial? Journal of Clinical Endocrinology and Metabolism 201196 38-52. (doi:10.1210/jc.2010-0266)

10 Handelsman DJ. Pharmacoepidemiology of testosterone prescribing in Australia, 1992-2010. Medical Journal of Australia 2012 196 642-645. (doi:10.5694/mja11.11277)

11 Gan E, Pattman S, Quinton R \& Pearce S. A UK epidemic of testosterone prescribing 2000-2010: 'never mind the testes'. Endocrine Abstracts $2012 \mathbf{2 8} 39$.

12 Institute of Medicine: Committee on Assessing the Need for Clinical Trials of Testosterone Replacement Therapy. In Testosterone and Aging: Clinical Research Directions. Eds Catharyn T. Liverman \& Dan German Blazer. Washington, DC 20001: National Academies Press, 500 Fifth Street, N.W., 2004.

13 United States Food and Drug Administration. Postmarket Reviews - vol 2, number 3, 2009.

14 Haring R, Ittermann T, Voelzke H, Krebs A, Zygmunt M, Felix SB, Grabe HJ, Nauck M \& Wallaschofski H. Prevalence, incidence and risk factors of testosterone deficiency in a population-based cohort of men: results from the study of health in Pomerania. Aging Male 201013 247-257. (doi:10.3109/13685538.2010. 487553)

15 Grossmann M. Low testosterone in men with type 2 diabetes: significance and treatment. Journal of Clinical Endocrinology and Metabolism 201196 2341-2353. (doi:10.1210/jc.2011-0118)

16 Keenan DM, Takahashi PY, Liu PY, Roebuck PD, Nehra AX, Iranmanesh A \& Veldhuis JD. An ensemble model of the male gonadal axis: illustrative application in aging men. Endocrinology 2006147 2817-2828. (doi:10.1210/en.2005-1356)
17 Vermeulen A, Kaufman JM \& Giagulli VA. Influence of some biological indexes on sex hormone-binding globulin and androgen levels in aging or obese males. Journal of Clinical Endocrinology and Metabolism 199681 1821-1826. (doi:10.1210/jc.81.5.1821)

18 Kalme T, Seppala M, Qiao Q, Koistinen R, Nissinen A, Harrela M, Loukovaara M, Leinonen P \& Tuomilehto J. Sex hormone-binding globulin and insulin-like growth factor-binding protein-1 as indicators of metabolic syndrome, cardiovascular risk, and mortality in elderly men. Journal of Clinical Endocrinology and Metabolism 200590 1550-1556. (doi:10.1210/jc.2004-0762)

19 Kupelian V, Page ST, Araujo AB, Travison TG, Bremner WJ \& McKinlay JB. Low sex hormone-binding globulin, total testosterone, and symptomatic androgen deficiency are associated with development of the metabolic syndrome in nonobese men. Journal of Clinical Endocrinology and Metabolism $2006 \quad 91 \quad 843-850$. (doi:10.1210/jc.2005-1326)

20 Lakshman KM, Bhasin S \& Araujo AB. Sex hormone-binding globulin as an independent predictor of incident type 2 diabetes mellitus in men. Journals of Gerontology. Series A, Biological Sciences and Medical Sciences 201065 503-509. (doi:10.1093/gerona/ glq002)

21 Vikan T, Schirmer H, Njolstad I \& Svartberg J. Low testosterone and sex hormone-binding globulin levels and high estradiol levels are independent predictors of type 2 diabetes in men. European Journal of Endocrinology 2010162 747-754. (doi:10.1530/EJE09-0943)

22 Bhasin S, Jasjua GK, Pencina M, D’Agostino R, Sr Coviello AD, Vasan RS \& Travison TG. Sex hormone-binding globulin, but not testosterone, is associated prospectively and independently with incident metabolic syndrome in men the Framingham Heart Study. Diabetes Care 201134 2464-2470. (doi:10.2337/dc110888)

23 Lee DM, O’Neill TW, Pye SR, Silman AJ, Finn JD, Pendleton N, Tajar A, Bartfai G, Casanueva F, Forti G et al. The European Male Ageing Study (EMAS): design, methods and recruitment. International Journal of Andrology 200932 11-24. (doi:10.1111/ j.1365-2605.2008.00879.x)

24 Lee DM, Pye SR, Tajar A, O’Neill TW, Finn JD, Boonen S, Bartfai G, Casanueva FF, Forti G, Giwercman A et al. Cohort Profile: The European Male Ageing Study. International Journal of Epidemiology 200938 374-378. (doi:10.1093/ije/dyn071)

25 Gallagher LM, Owen LJ \& Keevil BG. Simultaneous determination of androstenedione and testosterone in human serum by liquid chromatography-tandem mass spectrometry. Annals of Clinical Biochemistry $2007 \mathbf{4 4} 48-56$. (doi:10.1258/00045630777 9595922)

26 Vermeulen A, Verdonck L \& Kaufman JM. A critical evaluation of simple methods for the estimation of free testosterone in serum. Journal of Clinical Endocrinology and Metabolism $19998 \mathbf{8}$ 3666-3672. (doi:10.1210/jc.84.10.3666)

27 Washburn RA, Smith KW, Jette AM \& Janney CA. The PhysicalActivity Scale for the Elderly (PASE) - Development and evaluation. Journal of Clinical Epidemiology $1993 \mathbf{4 6} 153-162$. (doi:10.1016/0895-4356(93)90053-4)

28 TODAY Study Group. Design of a family-based lifestyle intervention for youth with type 2 diabetes: the TODAY study. International Journal of Obesity 2010 34 217. (doi:10.1038/ijo.2009.195)

29 Pi-Sunyer FX. Weight loss in type 2 diabetic patients. Diabetes Care 200528 1526-1527. (doi:10.2337/diacare.28.6.1526)

30 Morley JE, Kaiser FE, Perry HM, Patrick P, Morley PMK, Stauber PM, Vellas B, Baumgartner RN \& Garry PJ. Longitudinal changes in testosterone, luteinizing hormone, and folliclestimulating hormone in healthy older men. Metabolism $1997 \mathbf{4 6}$ 410-413. (doi:10.1016/S0026-0495(97)90057-3)

31 Zmuda JM, Cauley JA, Kriska A, Glynn NW, Gutai JP \& Kuller LH. Longitudinal relation between endogenous testosterone and cardiovascular disease risk factors in middle-aged men - A 13-year follow-up of former Multiple Risk Factor Intervention Trial participants. American Journal of Epidemiology 1997146 609-617. (doi:10.1093/oxfordjournals.aje.a009326) 
32 Liu PY, Beilin J, Meier C, Nguyen TV, Center JR, Leedman PJ, Seibel MJ, Eisman JA \& Handelsman DJ. Age-related changes in serum testosterone and sex hormone binding globulin in Australian men: longitudinal analyses of two geographically separate regional cohorts. Journal of Clinical Endocrinology and Metabolism 200792 3599-3603. (doi:10.1210/jc.2007-0862)

33 Strain GW, Zumoff B, Kream J. Strain JJ, Deucher R, Rosenfeld RS, Levin J \& Fukushima DK. Mild hypogonadotropic hypogonadism in obese men. Metabolism 198231 871-875. (doi:10.1016/ 0026-0495(82)90175-5)

34 Niskanen L, Laaksonen DE, Punnonen K, Mustajoki P, Kaukua J \& Rissanen A. Changes in sex hormone-binding globulin and testosterone during weight loss and weight maintenance in abdominally obese men with the metabolic syndrome. Diabetes, Obesity and Metabolism 20046 208-215. (doi:10.1111/j.14628902.2004.00335.x)

35 Coviello AD, Haring R, Wellons M, Vaidya D, Lehtimak IT, Keildson S, Lunetta KL, He C, Fornage M, Lagou V et al. A genome-wide association meta-analysis of circulating sex hormone-binding globulin reveals multiple loci implicated in sex steroid hormone regulation. PLoS Genetics 20128 e1002805. (doi:10.1371/journal.pgen.1002805)

36 Hammes A, Andreassen TK, Spoelgen R, Raila J, Hubner N, Schulz H, Metzger J, Schweigert FJ, Luppa PB, Nykjaer A et al. Role of endocytosis in cellular uptake of sex steroids. Cell 2005122 751-762. (doi:10.1016/j.cell.2005.06.032)

37 Gapstur SM, Gann PH, Kopp P, Colangelo L, Longcope C \& Liu K. Serum androgen concentrations in young men: a longitudinal analysis of associations with age, obesity, and race. The CARDIA male hormone study. Cancer Epidemiology, Biomarkers \& Prevention 200211 1041-1047. (doi:10.1016/j.ypmed.2006.12.004)

38 Gapstur SM, Kopp P, Gann PH, Chiu BCH, Colangelo LA \& Liu K. Changes in BMI modulate age-associated changes in sex hormone binding globulin and total testosterone, but not bioavailable testosterone in young adult men: the CARDIA Male Hormone Study. International Journal of Obesity 200731 685-691. (doi:10.1038/sj.ijo.0803465)

39 Wildman RP, Tepper PG, Crawford S, Finkelstein JS, SuttonTyrell K, Thurston RC, Santoro N, Sternfeld B \& Greendale GA. Do changes in sex steroid hormones precede or follow increases in body weight during the menopause? Results from the Study of Women's Health Across the Nation. Journal of Clinical Endocrinology and Metabolism 201297 E1695-E1704. (doi:10.1210/jc.2012-1614)

40 Thienpont LM, Van Uytfanghe K, Blincko S, Ramsay CS, Xie H, Doss RC, Keevil BG, Owen LJ, Rockwood AL \& Kushnir MM. State-of-the-art of serum testosterone measurement by isotope dilution liquid chromatography tandem mass spectrometry. Clinical Chemistry $2008 \mathbf{5 4}$ 1290-1297. (doi:10.1373/clinchem. 2008.105841)

Received 10 October 2012

Revised version received 27 November 2012

Accepted 14 December 2012 